\title{
PROJETO RESILIÊNCIA: ESTUDO LONGITUDINAL DAS TRAJETÓRIAS DE REINSERÇÃO FAMILIAR E SOCIAL DE CRIANÇAS E ADOLESCENTES QUE VIVEM EM SITUAÇÃO DE RISCO PSICOSSOCIAL EM RIO GRANDE/RS THE RESILIENCE PROJECT: LONGITUDINAL STUDY OF THE FAMILY AND SOCIAL TRAJECTORY OF CHILDREN AND ADOLESCENTS LIVING IN THE HIGH-RISK PSYCHOSOCIAL CONDITIONS IN RIO GRANDE/RS PROJECTO RESILIENCIA: ESTUDIO LONGITUDINAL DE LAS TRAYECTORIAS DE REINSERCIÓN FAMILIAR Y SOCIAL DE NIÑOS Y ADOLESCENTES QUE VIVEN EN SITUACIÓN DE RIESGO PSICO SOCIAL EN RIO GRANDE/RS
}

\author{
Mara Regina Santos da Silva', Karina da Silva Nunes², Flavia Lamberti Pivoto ${ }^{1}$, Daniela Brum da Silva', Ronídia Hendler \\ Schwanck', Francianne de Azevedo Giovanella ${ }^{1}$, Mônica Canilha Tortelli ${ }^{1}$ \\ ${ }^{1}$ Enfermeira. Doutora em Enfermagem. Professora do Departamento de Enferrmagem da Fundação Universidade Federal do Rio \\ Grande. Coordenadora da Pesquisa. \\ ${ }^{2}$ Acadêmicas do Curso de Enfermagem da Fundação Universidade Federal do Rio Grande. Bolsistas no Projeto de Pesquisa.
}

A infância vítima de maus tratos compreende o contingente de crianças e adolescentes que, de forma quotidiana, são violados em seus direitos de ser humano e de cidadãos, seja por omissão e/ou transgressão da família, da sociedade ou do Estadoํ. São pessoas vivendo em condições de risco psicossocial, expostas às mais variadas modalidades de violação: abuso físico, sexual, psicológico e negligência, entre outros. Essas crianças e adolescentes são aquelas para as quais pouco ou nada adiantou o Estatuto da Criança e do Adolescente (ECA) que, em seus princípios fundamentais, defende que elas devem receber proteção contra qualquer forma de negligência, crueldade e exploração, além de oportunidades e facilidades a fim de facultar seu desenvolvimento físico, mental, moral, espiritual e social, de forma normativa e em condições de liberdade e dignidade. Por diferentes razões, esses jovens acabam excluídos da proteção especial preconizada neste documento, pois, mesmo tendo seus direitos proclamados, continuam sendo vítimas do comportamento perverso de alguns adultos.

Estudos realizados em diversos Estados do Brasil revelam que os maus tratos são praticados, majoritariamente, por aquelas pessoas que, sob o ponto de vista afetivo, social e legal, têm a responsabilidade de

Endereço:

Mara Regina Santos da Silva

Rua Frederico Carlos de Andrade, 750

96208 050, Cassino, Rio Grande, RS

E-mail: mara@vetorial.net cuidar da criança e do adolescente, de manter a ordem em seu mundo e de preservar a estabilidade e previsibilidade em suas vidas. Ou seja, os familiares próximos (principalmente a mãe) que deveriam ser fonte de proteção, comportam-se como fonte de terror. Esta transformação do caráter protetor em caráter violento, geralmente, leva ao rompimento dos vínculos familiares e aumenta a possibilidade de institucionalização desses jovens.

Diversos programas voltados para a reinserção familiar e social de crianças e adolescentes vítimas de maus tratos são desenvolvidos no território nacional, alguns mantidos através de ação governamental, outros por iniciativa não-governamental. Em Rio Grande/RS, o Centro Municipal da Criança e do Adolescente (CEMCA), abriga jovens na faixa etária entre 08-18 anos, os quais são encaminhados pelo Conselho Tutelar. É um centro de atendimento integral que proporciona os cuidados básicos sociais, psicológicos e pedagógicos, tendo como meta principal a reinserção social e familiar de seus usuários.

Entretanto, mesmo priorizando os preceitos do ECA os programas de reinserção enfrentam um problema crítico desde o momento em que a criança/ adolescente é desligada da instituição para retornar à

Artigo original: Nota Prévia

Recebido em: 15 de fevereiro de 2004

Aprovação final: 15 de junho de 2004

Texto Contexto Enferm 2004 Jul-Set; 13(3):475-6. 
família. A partir desta etapa, geralmente, acontece uma interrupção do programa pois os profissionais perdem o contato com a família e, via de regra, seus filhos voltam a ser institucionalizados após um período de convivência tumultuada vivido mais tempo na rua do que em casa.

O retorno à família é, sem dúvida, um momento muito delicado do processo de reinserção, uma vez que lá, geralmente, permanecem vivos muitos dos problemas que contribuíram para a institucionalização da criança/adolescente e o rompimento dos vínculos familiares. Apesar desta importância, é justamente, nesta etapa que o acompanhamento dos profissionais e o suporte técnico para todos os envolvidos nesta situação é interrompido, muitas vezes, por falta de recursos materiais e humanos ou, não raro, por falta de conscientização da importância desse momento para a efetivação da reinserção, abrindo uma lacuna capaz de comprometer todo o processo.

Com o propósito de intervir neste momento crítico do processo, desenvolvemos este estudo cujo objetivo é construir, implementar e avaliar estratégias de intervenção para favorecer a reinserção familiar e social de crianças e adolescentes egressos de uma instituição destinada ao abrigo temporário de menores vítimas de maus tratos. É um estudo orientado pela concepção do desenvolvimento humano como um processo que pode desenrolar-se de forma normativa, mesmo a criança e o adolescente crescendo em um contexto com elevado potencial de risco, desde que eles encontrem suporte que possa ajudá-los no enfrentamento das adversidades que vivenciam.

Esta posição teórica está contemplada no conceito de resiliência que designa a capacidade de um ser humano construir uma trajetória de vida positiva, apesar de ele crescer em um contexto adverso ${ }^{2}$. A realidade na qual o sujeito vive pode ser ameaçadora, colocando em risco a qualidade de seu viver e fazendo-o sofrer, mas ele consegue encontrar recursos que o ajudam a avançar e prosseguir de forma positiva quando muitos de seus pares, em circunstâncias similares, não o conseguem.

Do ponto de vista metodológico, trata-se de um estudo longitudinal de natureza exploratória e descritiva, previsto para ser desenvolvido ao longo de três anos. A população é constituída de famílias moradoras no município de Rio Grande/RS, cujos filhos são vítimas de maus tratos e já estiveram institucionalizados, pelo menos uma vez no CEMCA. Os dados serão coletados em três etapas cada uma com finalidade específica e, posteriormente, submetidos à análise qualiquantitativa, de forma a responder ao objetivo proposto.

\section{REFERÊNCIAS}

1 Azevedo MA, Guerra VN, organizadores. Infância e violência doméstica : fronteiras do conhecimento. São Paulo : Cortez; 1993.

2 Cyrulnik B. Les vilains petits canards. Paris: Odile Jacob ; 2001. 